\title{
Troxerutin Reduces Kidney Damage against BDE-47-Induced Apoptosis via Inhibiting NOX2 Activity and Increasing Nrf2 Activity
}

\author{
Qun Shan, ${ }^{1,2}$ Juan Zhuang, ${ }^{1}$ Guihong Zheng, ${ }^{2}$ Zifeng Zhang, ${ }^{2}$ Yanqiu Zhang, \\ Jun Lu, ${ }^{2}$ and Yuanlin Zheng ${ }^{2}$ \\ ${ }^{1}$ School of Environment Science and Spatial Informatics, China University of Mining and Technology, Xuzhou, \\ Jiangsu Province 221008, China \\ ${ }^{2}$ Key Laboratory for Biotechnology on Medicinal Plants of Jiangsu Province, School of Life Science, Jiangsu Normal University, \\ 101 Shanghai Road, Xuzhou, Jiangsu Province 221116, China
}

Correspondence should be addressed to Yuanlin Zheng; ylzheng@jsnu.edu.cn

Received 17 April 2017; Accepted 18 June 2017; Published 15 October 2017

Academic Editor: Haobo Li

Copyright (c) 2017 Qun Shan et al. This is an open access article distributed under the Creative Commons Attribution License, which permits unrestricted use, distribution, and reproduction in any medium, provided the original work is properly cited.

2,2,4,4-Tetrabromodiphenyl ether (BDE-47), one of the persistent organic pollutants, seriously influences the quality of life; however, its pathological mechanism remains unclear. Troxerutin is a flavonoid with pharmacological activity of antioxidation and anti-inflammation. In the present study, we investigated troxerutin against BDE-47-induced kidney cell apoptosis and explored the underlying mechanism. The results show that troxerutin reduced renal cell apoptosis and urinary protein secretion in BDE-47-treated mice. Western blot analysis shows that troxerutin supplement enhanced the ratio of Bcl-2/Bax; inhibited the release of cytochrome $c$ from mitochondria, the activation of procaspase- 9 and procaspase-3, and the cleavage of PARP; and reduced FAS, FASL, and caspase- 8 levels induced by BDE-47. In addition, troxerutin decreased the production of reactive oxygen species (ROS) and increased the activities of antioxidative enzymes. Furthermore, troxerutin blunted Nrf2 ubiquitylation, enhanced the activity of Nrf2, decreased the activity of NOX2, and ameliorated kidney oxidant status of BDE-47treated mice. Together, these results confirm that troxerutin could alleviate the cytotoxicity of BDE- 47 through antioxidation and antiapoptosis, which suggests that its protective mechanism is involved in the inhibition of apoptosis via suppressing NOX2 activity and increasing Nrf2 signaling pathway.

\section{Introduction}

Polybrominated diphenyl ethers (PBDEs), a kind of persistent organic pollutants (POPs), have been emerging in tremendous danger on the global environment and human health. How to prevent and treat the damage of PBDEs has become a close attention. To find specific effective techniques and drugs against PBDEs in treatment, to a large extent, depends on the molecular mechanism underlying the effect of PBDEs on tissue damage. Among 209 homologues, 2,2,4,4-tetra-brominated diphenyl ether (BDE-47) is widely distributed in biological materials with high contents. Seriously, accumulation of BDE-47 in the body causes the severe damage of tissues including the liver, kidney, and adipose tissue [1-11]. For example, the homeostasis of parathyroid hormone is disturbed by BDE- 47 via decreasing the concentration of triiodothyronine (T3) and tetraiodothyronine (T4) in the blood serum of human or mouse [11]. Furthermore, the neurotoxicity of BDE-47 leads to a disordered behavior because of the decrease of synaptic protein in the central nervous system of mice $[5-7,9]$. Recent findings show that BDE-47 induces apoptosis of human embryonic kidney cells, resulting in metabolic dysfunction [12]. However, the toxicological effects and underlying mechanism of kidney damage induced by BDE- 47 in vivo are unclear.

Further studies show that natural products $\alpha$-tocopherol, omega- 3 polyunsaturated fatty acids, and troxerutin may be efficient candidate compounds against the damage induced 
by BDE-47 [13-16]. Troxerutin is a derivative of naturally occurring bioflavonoid rutin and enriched in fruits, vegetables, tea, coffee, and cereals. Due to its good solubility in water, troxerutin is easily absorbed by the gastrointestinal system and exhibits effectively protective function without cytotoxicity on tissues. Clinically, troxerutin has been available in the treatment of phlebocholosis and hemorrhoidal disease because it dredges the blood vessel well, improves the microcirculation, and protects the endothelial cells [17-19]; in addition, troxerutin possesses potential efficacy in the treatment of diabetic mellitus and Alzheimer's disease partly via its antioxidant activity [20, 21]. Recently, we find that troxerutin significantly reduced the damage of several tissues including the brain, liver, and kidney through ameliorating antioxidant level in D-galactose-induced aging mice [22-24] and, consequently, improved memory deficits via suppressing inflammatory response and oxidative stress $[25,26]$. Troxerutin enhanced the metabolism ability in lipid in high-fat diet-treated mice [27] and protected against liver damage caused by BDE-47 [15]. In the present study, we investigate the functional protective role of troxerutin in the kidney and the mechanism underlying the impairment caused by BDE-47 in a C57BL/6J mouse model.

\section{Materials and Methods}

2.1. Animal and Treatment. The dose of BDE-47 $(50 \mathrm{mg} / \mathrm{kg} /$ day) was based on the previous data [15] and our preliminary experiments (seen in Supplement materials available online at https://doi.org/10.1155/2017/6034692). Male C57BL/6J mice (6 weeks) were obtained from the Branch of National Breeder Center of Rodents (Beijing Vital River Laboratory Animal Technology Co. Ltd., Beijing, China). The mice were kept under the conditions of constant temperature $\left(22-24^{\circ} \mathrm{C}\right)$ and humidity (60\%) and a $12 \mathrm{~h}$ light/dark schedule and given free access to normal food and water. After one week of acclimatization to the conditions, mice were randomly divided into four groups including control group, BDE-47treated group, BDE-47/troxerutin-cotreated group, and troxerutin-treated group. BDE47-treated mice were administrated orally with BDE-47 at a dose of $50 \mathrm{mg} / \mathrm{kg} / \mathrm{d}$ [ $>98 \%$ purity, Chem Service, West Chester, PA, USA] or its solvent (corn oil) for 12 weeks. Troxerutin treatment was as follows: four hours after BDE-47 administration, the mice of BDE-47 + troxerutin and troxerutin groups obtained $100 \mathrm{mg} / \mathrm{kg} / \mathrm{day}$ troxerutin (dissolved in distilled water containing $0.1 \%$ Tween 80; >99\% purity, Baoji Fangsheng Biotechnology Co. Ltd., Baoji, China) by gavage, and the mice of the control and BDE-47 groups were given equal solvent. All procedures in the experiment were conformed to the legislation on the use and care of laboratory animals and were approved by the respective university committee for animal experiments. After 12 weeks, mice were sacrificed and kidney tissues were used for experiments or stored at $-80^{\circ} \mathrm{C}$ for later use.

2.2. Urine Collection and Determination of Albumin and Creatinine. Urine samples were collected from the mice housed in metabolic cages for $24 \mathrm{~h}$. The excretion of urine protein was evaluated using urine albumin-to-creatinine ratio (ACR) in $24 \mathrm{~h}$ urine collections. The content of urine creatinine and albumin was measured using the commercial kits (Jiancheng Institute of Biotechnology, Nanjing, China). The absorbed value was examined by ultraviolet/visible spectrometer (UV-2501PC, Shimadzu, Japan).

\subsection{Determination of Redox Status}

2.3.1. ROS Assay. Reactive oxygen species (ROS) was measured as OxiSelect ${ }^{\mathrm{TM}}$ In Vitro ROS/RNS Assay Kit (Cell Biolabs Inc., San Diego, CA, USA). In brief, mice were deeply anaesthetized and sacrificed. The kidney tissues were immediately separated, homogenized, and sonicated in ice cold 1/20 $(w / v) 50 \mathrm{mM}$ phosphate buffer saline solution (PBS, pH 7.2). Homogenates were centrifuged at $10000 \mathrm{~g}$ for $5 \mathrm{~min}$ to obtain the supernatants for detecting the level of ROS. $50 \mu \mathrm{l}$ ( $\left.V_{\text {homogenate: PBS }}=1: 4\right)$ homogenate samples were added to wells of a 96-well plate for fluorescence assay and then added with $50 \mu \mathrm{l}$ of catalyst to each well, mixed well, and incubated 5 minutes at room temperature. $100 \mu \mathrm{l}$ of fluorescent probe 2,7-dichlorofluorescein diacetate (DCFH-DA) was added to each well and incubated at room temperature under dark conditions. After $30 \mathrm{~min}$ of incubation, the conversion of DCFH-DA to the fluorescent product DCF was measured using a spectrofluorometer with excitation at $484 \mathrm{~nm}$ and emission at $530 \mathrm{~nm}$. Blanks were included to correct for background fluorescence (conversion of DCFH-DA in the absence of homogenate). ROS formation was quantified from a DCF standard curve. Data are expressed as nmol of DCF formed per minute per mg of protein.

\subsubsection{The Determination of Antioxidant Indexes of Kidney}

Tissue. The renal tissues were taken out and homogenized in $1: 5(w / v)$ pH 7.2 PBS buffer with 10 strokes at $1200 \mathrm{rpm}$ in a Potter homogenizer at $4^{\circ} \mathrm{C}$. The homogenates were centrifuged at $3000 \mathrm{rpm}$ for $15 \mathrm{~min}$ at $4^{\circ} \mathrm{C}$, and the supernatants were collected for the detection of the following indices: glutathione $(\mathrm{GSH})$, superoxide dismutase (SOD), catalase (CAT), and glutathione peroxidase (GPx). The experimental procedures were strictly carried out according to the kit instructions (Nanjing Jiancheng Bioengineering Institute, Nanjing, China). GSH content, GPx activity, and SOD activity were expressed as U/mg protein, and CAT activity was showed as $\mathrm{nM} \mathrm{H} \mathrm{H}_{2} \mathrm{O}_{2}$ decomposed/min/mg protein.

2.4. Apoptosis Detection. Terminal deoxynucleotidyl transferase-mediated dUTP nick end labeling (TUNEL) assay was performed on $4 \%$ paraformaldehyde (PFA) fixed sections of the kidney tissue and was carried out according to the instruction of in situ cell death detection kit (Roche Biomedical Laboratories Inc., Burlington, Germany). The protocol is as follows: the sections were fixed in 4\% PFA in $\mathrm{pH}$ 7.2 PBS at room temperature for $20 \mathrm{~min}$ and then washed $3 \times 5 \mathrm{~min}$ in $\mathrm{pH} 7.2 \mathrm{PBS}$ buffer. The sections were permeabilized in pepsin digest all at $37^{\circ} \mathrm{C}$ for $40 \mathrm{~min}$ and washed $3 \times 10 \mathrm{~min}$ in PBS. Thirdly, the sections were incubated in enzyme reaction mix (enzyme solution: label solution $=1: 9 \mathrm{~V}$ ) for $1 \mathrm{~h}$ at $37^{\circ} \mathrm{C}$ in a black wet box and then washed $3 \times 10 \mathrm{~min}$ in PBS. At last, the nuclei were stained with 4,6-diamidino-2-phenylindole (DAPI, Sigma-Aldrich 
Co., St. Louis, MO, USA) at room temperature for $30 \mathrm{~min}$. The sections were cover-slipped with glycerol-PBS $(3: 1 \mathrm{v} / \mathrm{v})$ and examined by Leica 4000 at $488 \mathrm{~nm}$ and $350 \mathrm{~nm}$ (Leica, CA, Germany). The percentage of apoptosis was calculated using the following formula: Percentage of apoptosis $(\%)=$ numbers of apoptosis cells/total numbers of detected cells $* 100 \%$.

2.5. Immunofluorescence. The mice were anesthetized and transcardially perfused with $0.9 \%$ sterile saline, and after, the kidneys were prefixed with a little of $4 \%$ PFA/PBS, pH 7.2 , then removed promptly and post-fixed in 4\% PFA/PBS at $4^{\circ} \mathrm{C}$ for $4 \mathrm{~h}$, and incubated successively in $15 \%, 20 \%$, and $30 \%$ sucrose/pH 7.2 PBS solution to make them sink. At last, the kidneys were embedded in optimal cutting temperature (OCT) compound (Leica, CA, Germany). $12 \mu \mathrm{m}$ cryosections were collected by using Leica 3050 (Leica, CA, Germany) for immunofluorescence.

Immunofluorescence was performed as follows: after $1.5 \mathrm{~h}$ drying at $37^{\circ} \mathrm{C}$, the sections were carried out for antigen retrieval in boiling $0.1 \mathrm{~mol} / \mathrm{l}$ sodium citrate buffer for $15 \mathrm{~min}$ and incubated in $\mathrm{pH} 7.2 \mathrm{PBS}$ buffer [including $0.3 \%$ Triton100 or Tween- 20 and $5 \%$ bovine serum albumin (BSA)] at $25^{\circ} \mathrm{C}$ for $1 \mathrm{~h}$ to block nonspecific binding site. Then, the sections were incubated overnight with rabbit antinuclear factor E2-related factor 2 (Nrf2, 1:500, ab62352) and rabbit antinicotinamide adenine dinucleotide phosphate oxidase 2 (NOX2, 1:500, ab80508), and related fluorescence secondary antibody was added for incubation of $1 \mathrm{~h}$ at $25^{\circ} \mathrm{C}$. After DAPI was applied for $5 \mathrm{~min}$, the sections were captured using Leica microscope.

2.6. Western Blot. The mice were deeply anaesthetized and sacrificed. The kidney tissues were immediately excised and homogenized in $1 / 5(w / v)$ tissue protein extraction reagent (Thermo Fisher Scientific Inc., Waltham, MA, USA) and the protease inhibitor. The cold tissues were homogenized two times for $28 \mathrm{~s}$ with $30 \mathrm{~s}$ intervals using MM400 (Retsch $\mathrm{GmbH}$, Haan, Germany) and centrifuged at $14000 \mathrm{~g}$ for $30 \mathrm{~min}$ at $4^{\circ} \mathrm{C}$ to obtain the supernatants, and then, the supernatants were collected and stored at $-86^{\circ} \mathrm{C}$ for Western blot analyses. The expression levels of apoptosome containing heme oxygenase 1 (HO-1), apoptosis protease-activating factor-1 (APAF-1), caspase-3, cleaved-caspase-3, B-cell lymphoma-2 (Bcl-2), Bcl-2-associated X protein (Bax), poly ADP ribose polymerase (PARP), cytochrome $c$, factorassociated suicide (FAS), Fas ligand (FASL), caspase-8, and NOX2 were assessed by Western blotting. Nrf2 levels in the cytoplasm and nuclear extracts of kidney tissues were assessed by Western blotting, which was obtained by a nuclear/cytoplasm fractionation kit (BioVision Inc., USA). Protein contents of the supernatants were measured by the bicinchoninic acid assay kit (Pierce Biotechnology Inc., Rockford, IL, USA).

Western blot analyses were performed following standard procedures. The supernatant proteins $(30 \mu \mathrm{g})$ were separated using sodium dodecyl sulfate polyacrylamide gel electrophoresis (SDS-PAGE, 120 V). Objective bands were transferred to a polyvinylidene difluoride membrane (PVDF;
Roche Diagnostics Corporation, Basel, Switzerland) by $350 \mathrm{~mA}$ electrophoretic transfer. The membrane was blocked with $5 \%$ nonfat milk or $5 \%$ BSA in Tris-buffered saline (TBS, $\mathrm{pH} 7.2$, containing $0.1 \%$ Tween-20) for $1 \mathrm{~h}$ at room temperature and incubated at $4^{\circ} \mathrm{C}$ overnight with the following primary antibodies, respectively: mouse anticytochrome c (15 KD, 31 KD, 45 KD, 1:1000, BD556432, Becton, Dickinson and Company Inc., Franklin Lakes, USA) and rabbit anti-Bax (22 KD, 1:1000, BD556467), rabbit anti-APAF-1 (130 KD, 1:1000, BD559683), rabbit anti-caspase-9 (37 KD, $39 \mathrm{KD}, 49 \mathrm{KD}$, CST9504, Cell Signaling Technology Inc., Beverly, MA), rabbit anti-FASL ( $31 \mathrm{KD}$, ab15285), rabbitcaspase-12 (42 KD, $55 \mathrm{KD}$, CST2202), rabbit anti-FAS (48 KD, sc1032, Santa Cruz Biotechnology Inc., Dallas, TX, USA), mouse anti- $\beta$-actin ( $42 \mathrm{KD}, 1: 2000$, Chemicon International Inc., California, USA), rabbit anti-Nrf2 (100 KD, ab62352), caspase-8 (18 KD, $43 \mathrm{KD}$, CST8592), rabbit antiHO-1 (33 KD, ab68477), rabbit anti-PARP (55 KD, ab16572), and rabbit anti-NOX2 (65 KD, ab80508). Protein bands were detected using horseradish peroxidase- (HRP-) conjugated anti-rabbit or anti-mouse secondary antibodies (Cell Signaling Technology, Danvers, MA, USA). Protein bands were detected using FluorChem $M$ system (Protein Simple, CA, USA). The mean optical density (OD) values of protein bands were measured with Scion image analysis software (Scion Corp., Frederick, MD, USA) and were normalized to mouse anti- $\beta$-actin as internal controls (OD detected protein/OD internal control).

2.7. Immunoprecipitation Assay. $30 \mathrm{mg}$ kidney tissues were homogenized in protein immunoprecipitation buffer including $1 \times \mathrm{pH} 7.2 \mathrm{PBS}, 1 \%$ Triton $\mathrm{X}-100$, and the protease inhibitor. The cold tissues were homogenized two times for $28 \mathrm{~s}$ with $30 \mathrm{~s}$ intervals using MM400 (Retsch $\mathrm{GmbH}$, Haan, Germany) and centrifuged at $14000 \mathrm{~g}$ for $30 \mathrm{~min}$ at $4^{\circ} \mathrm{C}$ to obtain the supernatants. After the supernatants were carried out to measure the protein content, $100 \mu \mathrm{g}$ protein supernatants were added $10 \mu \mathrm{l}$ of resuspended volume of protein $\mathrm{A} / \mathrm{G}$ plus agarose and incubated for $30 \mathrm{~min}$ to wipe off the nonspecific adsorption. Then, the supernatants were added $2 \mu \mathrm{g}$ Nrf2 primary antibody (sc-30915) and incubated for $1 \mathrm{~h}$ at $4^{\circ} \mathrm{C}$ on a rotating device. And $20 \mu \mathrm{l}$ of resuspended volume of protein $\mathrm{A} / \mathrm{G}$ plus agarose was added and incubated vibrationally overnight. The immunoprecipitates were collected by centrifugation at $1000 \mathrm{~g}$ for $5 \mathrm{~min}$ at $4^{\circ} \mathrm{C}$. The pellets were washed for 4 times with $1 \mathrm{ml}$ immunoprecipitation buffer, each time repeating centrifugation step above. After the final wash, the pellets were resuspended in $40 \mu \mathrm{l}$ of $1 \times$ electrophoresis sample buffer. The samples were boiled for $3 \mathrm{~min}$ and analyzed $20 \mu \mathrm{l}$ aliquots by SDS-PAGE for ubiquitination (ab19247).

2.8. Statistical Analysis. All the data were analyzed by the software SPSS 15.0 (SPSS Software Inc., Chicago, IL, USA) statistically. Cell apoptosis rate, ROS level, GSH level, antioxidant enzyme activity, and Western blotting results were analyzed with Tukey's HSD post hoc test. Data were expressed as mean \pm SEM and $p<0.05$ was considered statistically significant. 


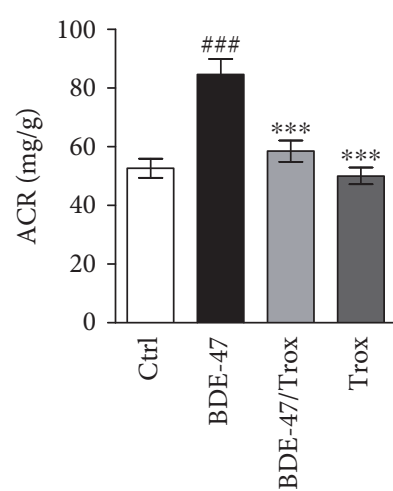

(a)

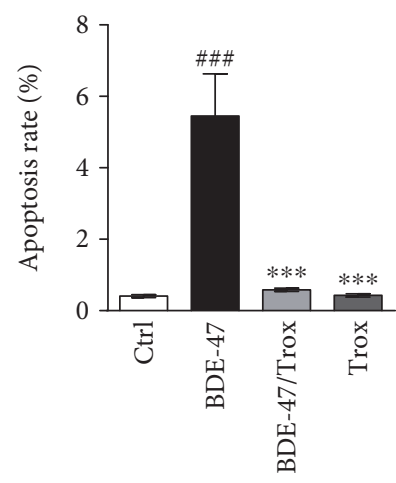

(c)

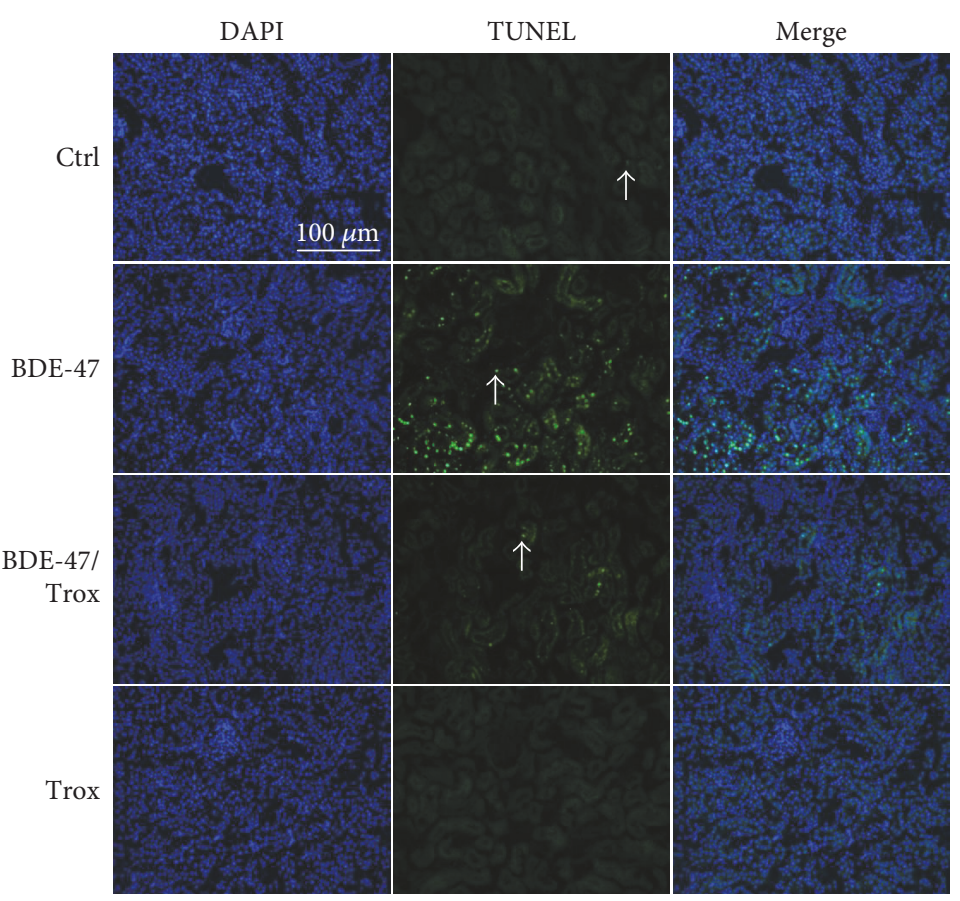

(b)

FIgURE 1: Troxerutin reduces ACR and kidney cell apoptosis in BDE-47 treated mice. (a) ACR (albumin-to-creatinine, mg/g, $n=8$ ) was tested at 12 weeks after BDE-47 was orally treated. (b) Kidney cell apoptosis was examined by the use of TUNEL assay (20x). White arrows (green fluorescence) represent positive signals. 4',6-Diamidino-2-phenylindole (DAPI) was used to stain the nuclei blue. Scale bar, $100 \mu \mathrm{m}$. (c) TUNEL-positive cells were quantitatively analyzed in the kidney tissue by the use of Turkey's HSD post hoc test. Ctrl: control group; BDE-47: BDE-47-treated group; BDE-47 + Trox: BDE-47 and troxerutin cotreated group; Trox: troxerutin-treated group. Data were presented as mean $\pm \operatorname{SEM}(n=5) .{ }^{* * *} p<0.001$ versus BDE- 47 -treated group. ${ }^{\# \# \#} p<0.001$ versus control group.

\section{Results}

3.1. Troxerutin Inhibits Kidney Cell Apoptosis Induced by $B D E-47$ in the Mice. Several tissues exhibit dysfunction caused by BDE-47, but it is unknown whether BDE-47 impairs the kidney in vivo. Therefore, we firstly used biochemical analysis and TUNEL assay to examine the change of kidney function and cell apoptosis of C57BL/6J mice treated with BDE-47. We found that BDE- 47 treatment in mice significantly increased the ratio of albumin to creatinine (ACR, Figure 1(a)) and the number of kidney apoptosis cells compared to the untreated mice (Figures 1(b) and 1(c)). Orally administration of troxerutin in BDE-47-treated mice substantially reduced ACR and the ratio of kidney apoptosis cells compared to alone BDE-47-treated mice. However, there was no statistical difference among cotreated group with BDE-47 and troxerutin, troxerutin-treated group, and control group.

3.2. Troxerutin Ameliorates Kidney Mitochondrial Injury in BDE-47-Treated Mice. Proapoptotic (Bax, Bad, etc.) and antiapoptotic (Bcl-2, Bcl-xL, etc.) proteins in Bcl-2 family regulate the process of apoptosis. We observed that BDE-47 treatment caused a markedly decline in Bcl-2 expression and an increase in Bax expression; however, troxerutin supplementation restored the ratio of $\mathrm{Bcl}-2$ to Bax (Figure 2(a)). The reduction of $\mathrm{Bcl}-2 / \mathrm{Bax}$ ratio triggered cytochrome $\mathrm{C}$ transferring from the mitochondria to the cytoplasm. Additionally, BDE-47 reduced the number of mitochondrial cytochrome $c$ fraction and elevated the number of cytosolic cytochrome $c$ fraction (Figure 2(b)). However, troxerutin supplementation reversed the change and restored the location of cytochrome c; at the same time, we found that troxerutin inhibited the increase of APAF-1 protein induced by BDE-47 (Figure 2(b)), but troxerutin treatment alone did not alter these parameters (Figures 2(a) and 2(b)).

3.3. Troxerutin Blocks the Activities of Kidney Caspase Proteins in BDE-47-Treated Mice. The release of cytochrome $c$ from the mitochondria to the cytoplasm promotes the forming of apoptosome containing APAF-1, cytochrome $c$, and procaspase- 9 ; then, procaspase- 9 is turned into caspase- 9 to activate the downstream executioners caspase-3, caspase-6, and caspase-7, resulting in PARP cleavage, and initiates cell 


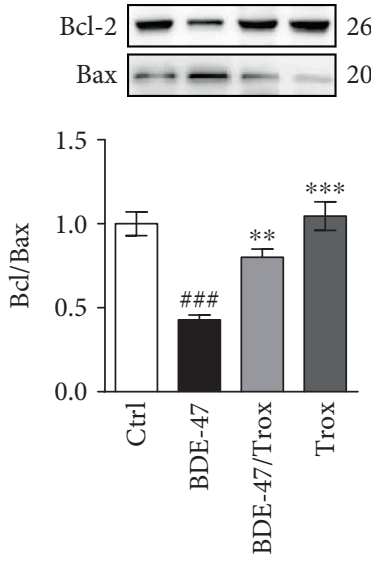

(a)
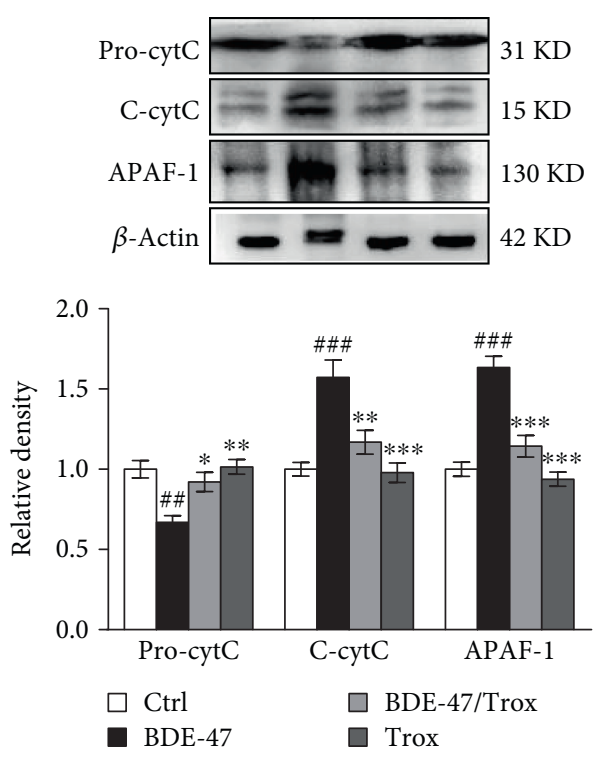

(b)

FIgURE 2: Troxerutin inhibited mitochondria abnormality caused by BDE-47. (a) Bcl-2 and Bax were measured by the use of Western blot analysis. (b) Cytochrome $\mathrm{c}$ and APAF-1 were detected by Western blot analysis. Pro-cytC means pro-cytochrome $\mathrm{c}$ in the mitochondria and c-cytC means cleaved cytochrome $\mathrm{c}$ in the cytosol. Data were showed as mean \pm SEM $(n=5) .{ }^{*} p<0.05,{ }^{* *} p<0.01$, and ${ }^{* * *} p<0.001$ versus BDE-47-treated group. ${ }^{\# \#} p<0.01$ and ${ }^{\# \# \#} p<0.001$ versus control group.

apoptosis. We found that BDE-47 had no significant effect on procaspase-9 level (Figure 3(a)) and remarkably increased procaspase-3 level (Figure 3(b)), enhanced the levels of cleaved caspase- 9 and cleaved caspase- 3 , and consequently promoted the cleavage of PARP (Figure 3(b)). We observed the increase of FAS, FASL, and cleaved caspase- 8 in the kidney of BDE-47-treated mice, while there was no significant change of procaspase- 8 expression compared to control group (Figures 3(c) and 3(d)). However, troxerutin inhibited the activation of caspase- 9 and caspase- 3 and reduced the level of cleaved PARP, FAS, FASL, and cleaved caspase-8. There was no significant difference among control group, BDE-47 and troxerutin cotreated group, and troxerutin group.

\subsection{Troxerutin Increases Kidney Antioxidant Capacity in} BDE-47-Treated Mice. Increasing ROS formation plays a key role in the tissue damage induced by BDE- 47 . To investigate whether troxerutin inhibits oxidative stress, we observed the levels of ROS and glutathione (GSH) and the activities of antioxidative enzymes. The results showed BDE-47 treatment led to a pronounced increase of ROS generation (Figure 4(a)) and a decrease of GSH content (Figure 4(b)) in the mouse kidney while troxerutin administration reduced ROS content and enhanced GSH level, then protected the mouse kidney against oxidative insult. Additionally, we found that BDE-47 significantly alleviated the activities of GPx (Figure 4(c)), SOD (Figure 4(d)), CAT (Figure 4(e)), and HO-1 (Figure 4(f)) in the kidney of mice compared to control mice, and troxerutin administration inhibited the reduction of the activities of these antioxidant enzymes.
3.5. Troxerutin Enhances Kidney Nrf2 Activity in BDE-47Treated Mice. Nrf2, a major ROS-regulating effector, induces the increase of many antioxidative genes, such as SOD, CAT, GPx, and HO-1, via binding to their promoters [28]. Then, we investigated the status of the intracellular antioxidant defense mechanisms by detecting the activity of Nrf2. The results showed that BDE-47 administration significantly increased the expression of Nrf2-binding protein Keap1 (Kelch-like ECH-associated protein 1) in the kidney tissue of mice compared to control group (Figure 5(a)), resulting in the increase of Nrf2 ubiquitylation (Figure 5(b)) and in the reduction of nuclear Nrf2 activity (Figure 5(a)). However, troxerutin supplementation decreased the ubiquitination of Nrf2 and increased the activity of nuclear Nrf2 in the kidney of BDE-47-treated mice. Immunofluorescence staining showed a strong expression signal of Nrf2 presented in the cytoplasm; however, there was a weak signal in the nuclear after treating mice with BDE-47, and furthermore, troxerutin blocked this abnormal change (Figure 5(c)). The results suggest that troxerutin enhanced the activity of Nrf2 and prevented the kidney damage induced by BDE- 47 .

3.6. Troxerutin Inhibits Kidney NOX2 Expression in BDE-47Treated Mice. NOX2, one of NADPH oxidases, is richly expressed in kidney tubular cells and endothelial cells and identified as a major source of oxidative stress in renal disease progression [29]. The results showed that BDE-47 supplement markedly raised the activity of NOX2, which was reversed by troxerutin (Figure 6(a)). There was no significant difference among control, cotreated group with BDE-47/ troxerutin, and troxerutin group. Figure 6(b) also shows that 

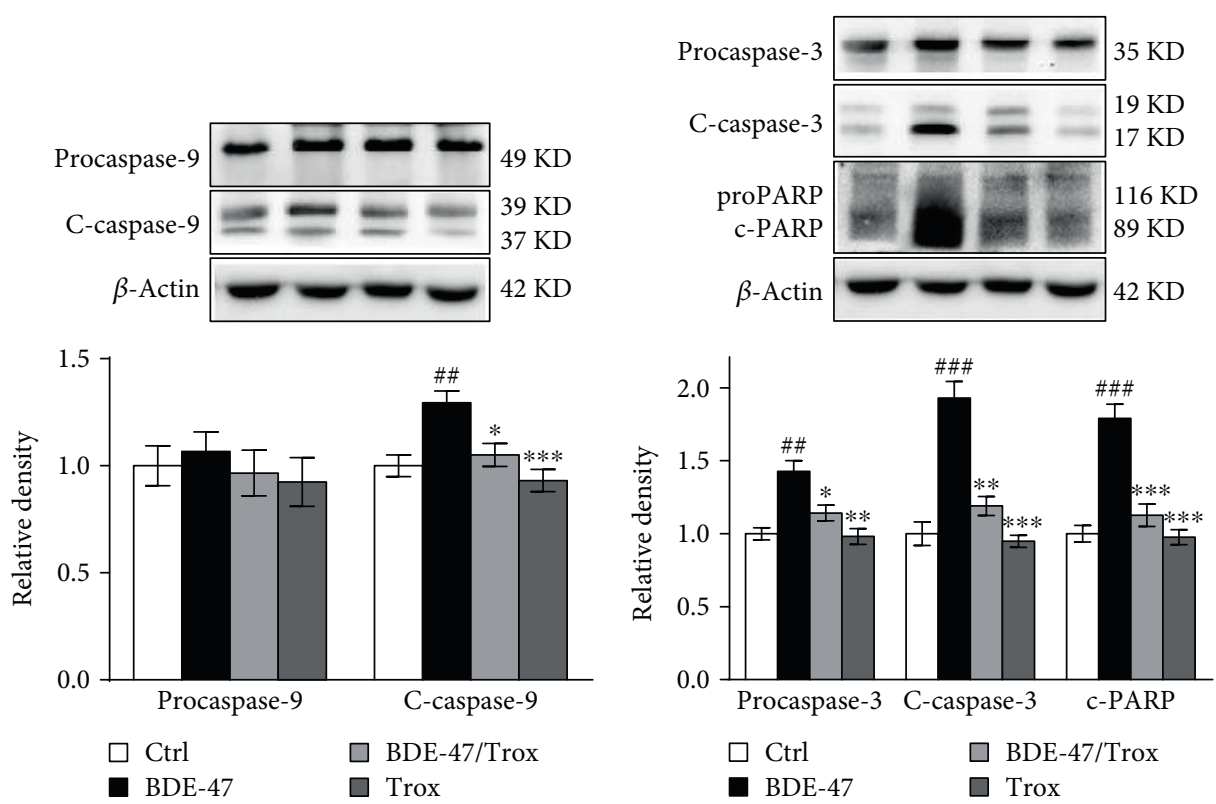

(a)

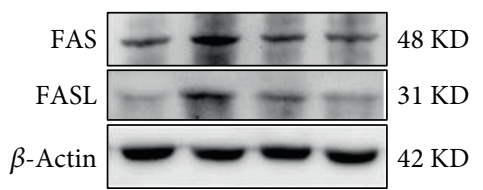

(b)
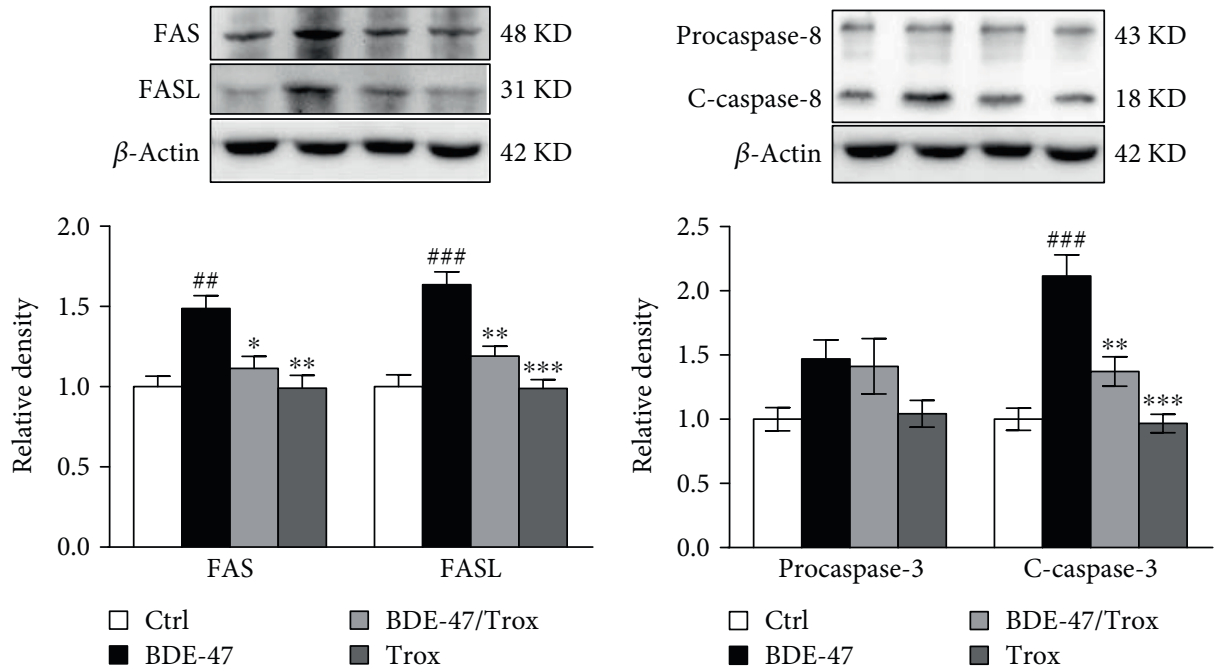

(c)

(d)

Figure 3: Troxerutin antagonizes BDE-47 induced expression of kidney apoptosis molecules. (a) Procaspase-9 and cleaved caspase-9 (c-caspase-9) were examined by Western blot analysis. (b) Procaspase-3, cleaved caspase-3 (c-caspase-3), proPARP, and cleaved PARP (c-PARP) were detected by Western blot. (c) FAS and FASL were detected by Western blot. (d) Procaspase- 8 and cleaved caspase- 8 (c-caspase-8) were measured by Western blot. Data were expressed as mean \pm SEM $(n=5)$. ${ }^{*} p<0.05,{ }^{* *} p<0.01$, and ${ }^{* * *} p<0.001$ versus BDE-47-treated group. ${ }^{\# \#} p<0.01$ and ${ }^{\# \# \#} p<0.001$ versus control group.

there was a strong fluorescence signal in kidney cell membrane in BDE-47-treated mice, while troxerutin treatment significantly attenuated fluorescence signal of NOX2 induced by BDE- 47 .

\section{Discussion}

PBDEs are widely present in the household and environment and have attracted people's attention because of their toxic action on animals including neurotoxicity, reproductive toxicity, hepatotoxicity, and endocrine toxicity. PBDEs have been detected in the blood, lipid tissue, and breast milk of human [30-32], which makes up a potential health risk. The investigations show that PBDEs significantly affect infant birth weight and birth length, thyroid function in young children, and neurodevelopment [33, 34]. Furthermore, the toxicology of PBDEs is intimately associated with hydroxylated products of PBDEs [34, 35]. Among PBDE congeners, $\mathrm{BDE}-47$ has the highest concentration and the strongest toxicity in the environment. Oxidative stress has been demonstrated to play an important role in BDE-47's toxic action. Increasing data reveal that BDE-47 induces oxidative stress and in turn mediates DNA damage, mitochondrial dysfunction, and endoplasmic reticulum stress 


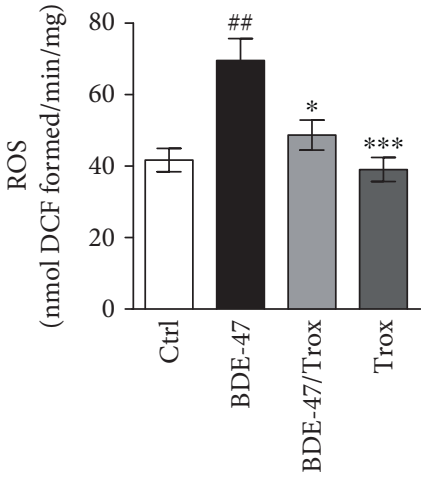

(a)

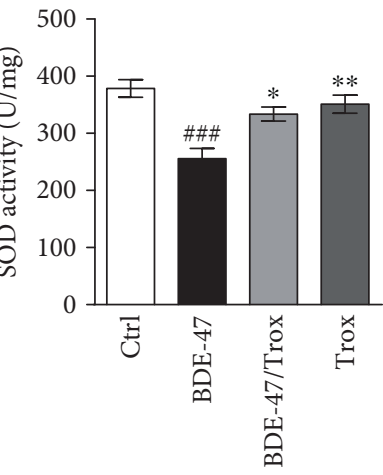

(d)

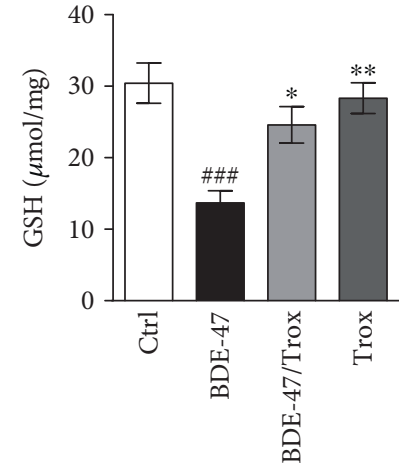

(b)

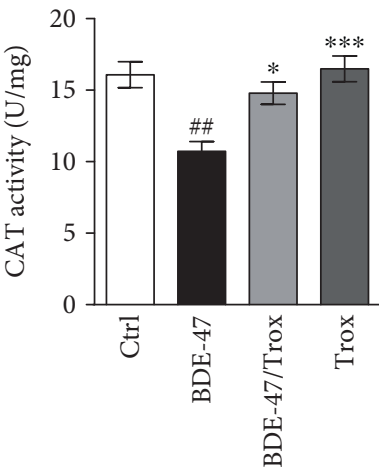

(e)

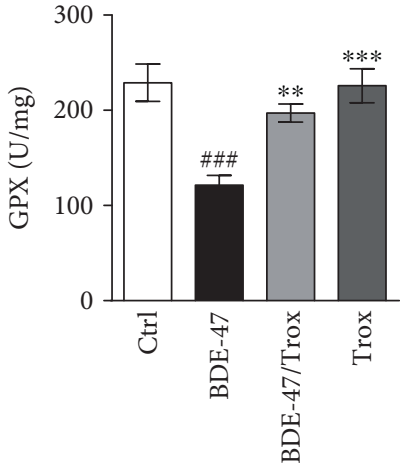

(c)
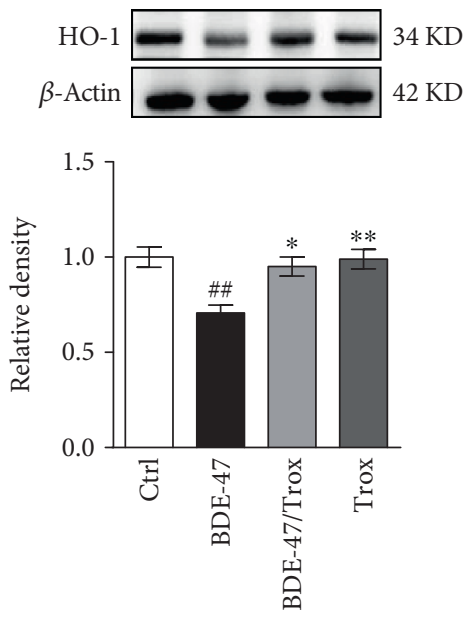

(f)

FIGURE 4: Troxerutin increases kidney antioxidative level in BDE-47-treated mice. (a) ROS level was examined by fluorescent probe DCFH-DA. (b-e): GSH content (b), GPx activity (c), SOD activity (d), and CAT activity (e) were measured by the use of biochemical assay. (f) HO-1 activity was assessed by Western blot analysis. Data were expressed as mean $\pm \operatorname{SEM}(n=5) .{ }^{*} p<0.05,{ }^{* *} p<0.01$, and ${ }^{* * *} p<0.001$ versus $\mathrm{BDE}-$ 47 -treated group. ${ }^{\# \#} p<0.01$ and ${ }^{\# \#} p<0.001$ versus control group.

$[16,36,37]$. Recently, antioxidants have been demonstrated to eliminate oxidative stress by scavenging ROS induced by BDE47 in vitro $[13,14,38]$. Interestingly, we find that troxerutin could effectively reduce oxidative stress-mediated $\mathrm{NAD}^{+}$ depletion and ameliorate liver inflammation injury. In this present study, we further found that troxerutin decreases renal cell apoptosis caused by BDE-47 via enhancing Nrf2 activity and blocking NOX2 activity in mice.

Oxidative stress is considered as a disorder between oxidant production and antioxidant defense system. The NADPH oxidase is a major ROS-generating enzyme, which has seven isoforms including NOX1-NOX5, Duox1, and Duox2. NOX2 (isoform 2, gp91phox), constitutively expressed in kidney tubular cells and endothelial cells, is identified as a major source of oxidative stress in kidney diseases [29]. BDE-47 accumulation can result in metabolic disorders such as the disruption of glycolipid metabolism, the reduction of testosterone, and the disruption of the seminiferous epithelium [39, 40], Herein, we observed that BDE-47 increased renal NOX2 expression and caused ROS accumulation in the kidney tissue of mice and might be associated with metabolic disorders [41], while troxerutin reversed the increase of NOX2 activity and ROS level, which is in line with flavonoid purple sweet potato color reducing the NOX2 activity by interrupting the assembly of catalytic subunit gp91phox and regulatory subunits in the brain of domoic acid-treated mice [42].

In vivo, there is a dynamic equilibrium between generation and elimination of free radical. NOX2 is a major ROS-generating enzyme, whereas Nrf2 is an important antioxidative transcription factor, which is bound with its inhibitor Keap1 in the cytoplasm under resting condition, where Keap 1 promotes the ubiquitination and proteasome degradation of Nrf2 via E3 ligase system [43]. Upon exposure to stress or to chemical inducers, Nrf2 is freed from Keap1, translocating to the nucleus and inducing the transcription of downstream genes including HO-1, SOD, GPx, and CAT which play vital roles in antioxidative response. The Keap1Nrf2 system is thought to be a crucial role in kidney oxidative injury and considered as a prospective target for kidney disease $[43,44]$, so proteasome inhibitor MG132 could inhibit Nrf2 proteasomal degradation and promote antioxidative activity, having the protective efficacy on diabetes nephropathy [45]. BDE-47 induced oxidative damage and 

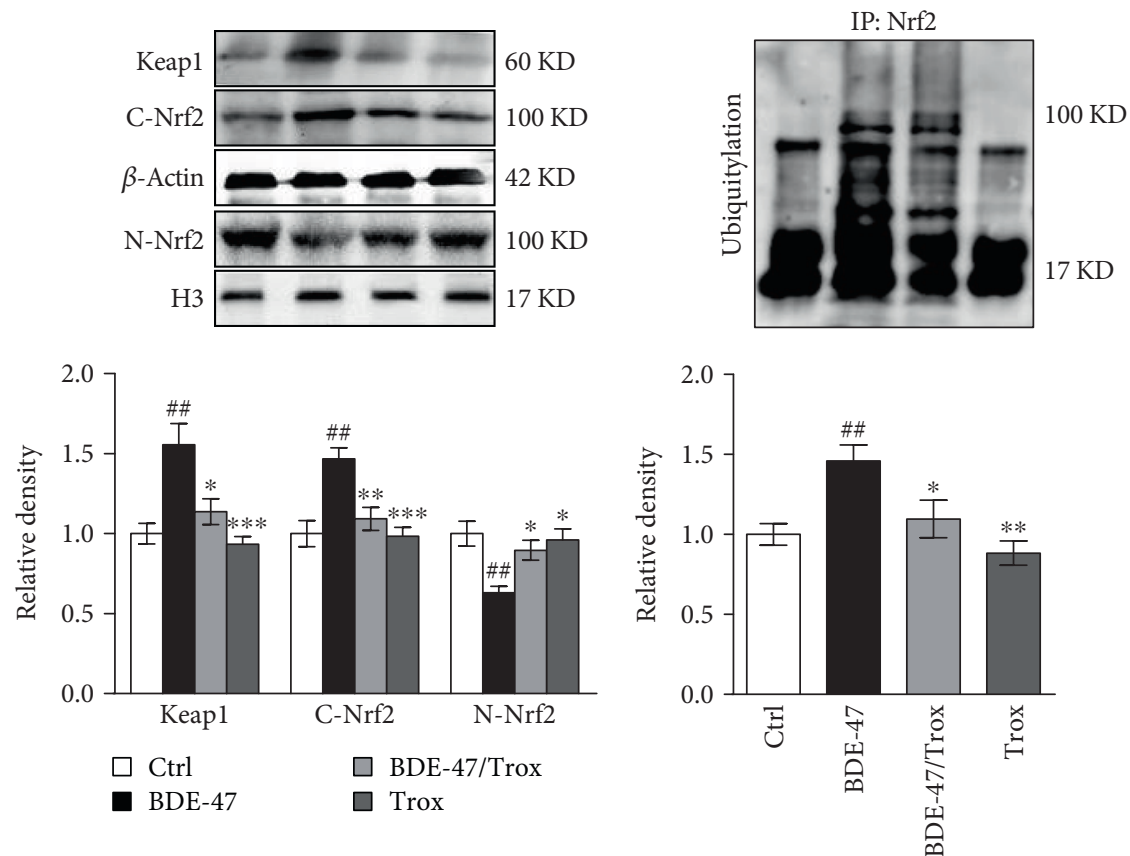

(a)

(b)
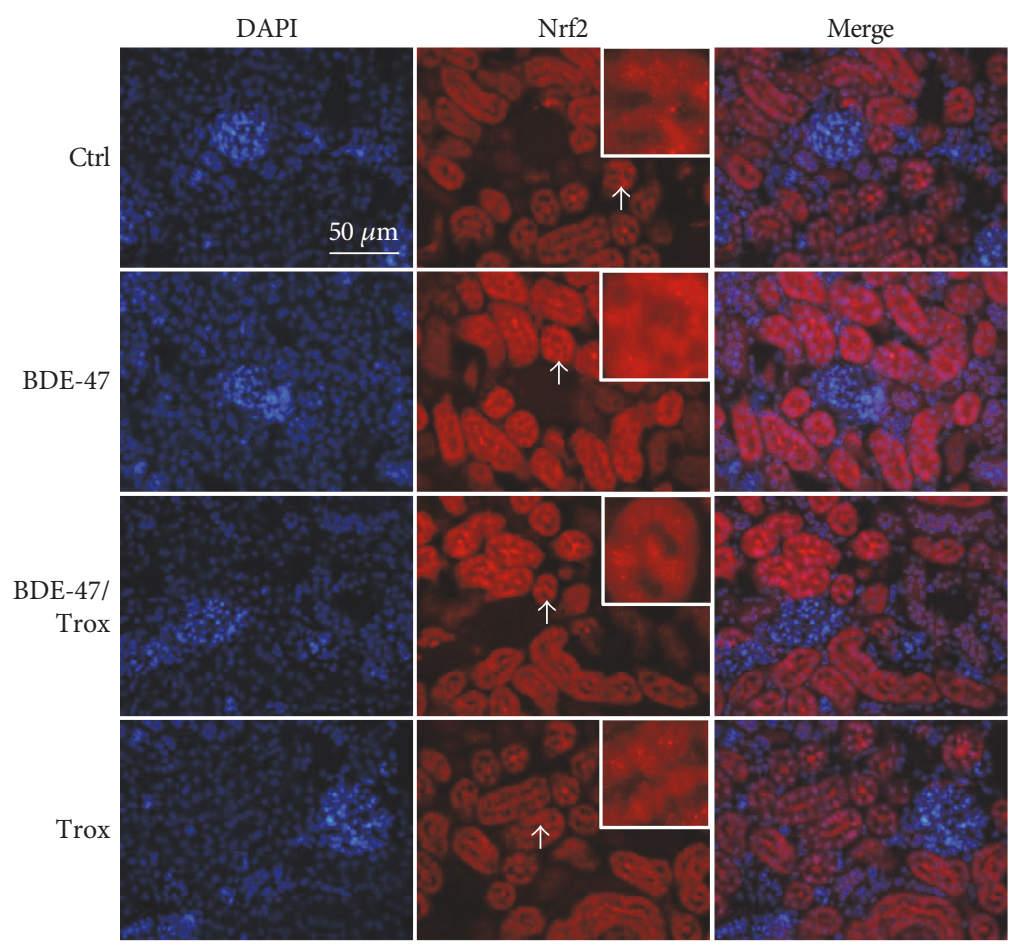

(c)

Figure 5: Troxerutin increases kidney Nrf2 activity in BDE-47-treated mice. (a) The activities of Keap1, cytoplasmic Nrf2, and nuclear Nrf2 were detected by Western blot assay. (b) Nrf2 ubiquitylation was evaluated by Western blot analysis after Nrf2 immunoprecipitation. (c) Nrf2 immunohistochemical staining. Green fluorescence represents positive signal, and DAPI was used to stain the nuclei blue. Scale bar, $50 \mu \mathrm{m}$. White arrow indicates positive signal which was placed in the upper right corner. Data were expressed as mean \pm SEM $(n=5) .{ }^{*} p<0.05$, ${ }^{* *} p<0.01$, and ${ }^{* * *} p<0.001$ versus BDE-47-treated group. ${ }^{\# \#} p<0.01$ versus control group.

inflammatory response in a human extravillous trophoblast cell line, HTR-8/SVneo, while pretreatment with tert-butyl hydroquinone or sulforaphane, known Nrf2 inducers, reduced the nuclear import of redox-sensitive transcription factor nuclear factor kappa B (NF- $\kappa \mathrm{B})$ and release of inflammatory factor interleukin 6 (IL-6) [46]. Previous reports 


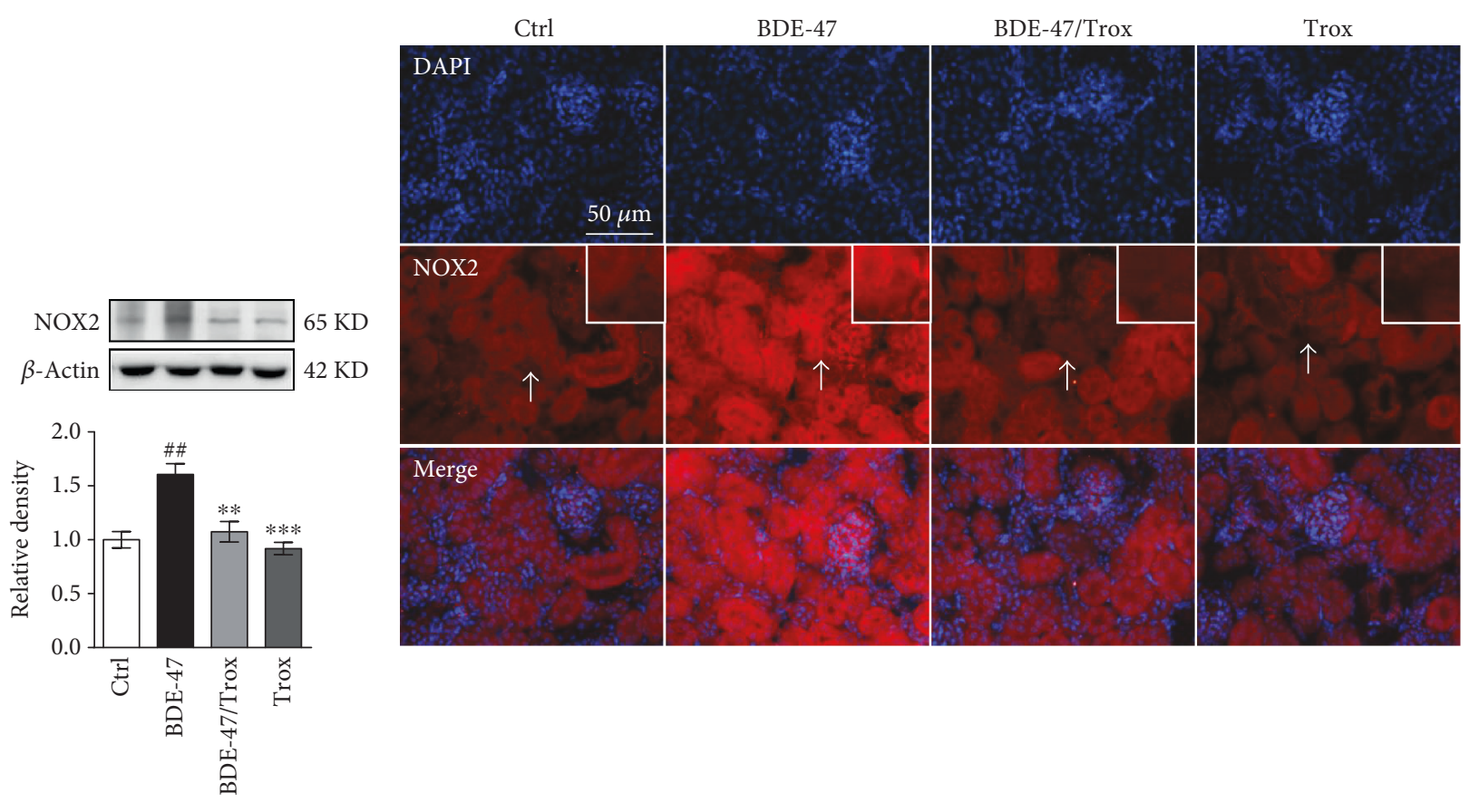

(a)

(b)

FIgure 6: Troxerutin decreases the activity of kidney NOX2 in BDE-47-treated mice. (a) NOX2 activity was evaluated by Western blot analysis. (b) NOX2 immunohistochemical staining. Green fluorescence represents positive signal, and DAPI was used to stain the nuclei blue. Scale bar, $50 \mu \mathrm{m}$. White arrows indicate positive signals which were placed in the upper right corner. Data were expressed as mean \pm SEM $(n=5) .{ }^{* *} p<0.01$ and ${ }^{* * *} p<0.001$ versus BDE-47-treated group. ${ }^{\# \#} p<0.01$ versus control group.

demonstrate that Keap1 is induced under diabetic nephropathy [47] and then whether BDE-47 as a diabetic prevalence factor regulates the level of Keap1 [39]. Here, we found that long-term treatment of BDE-47 increased Keap1 level and made Nrf2 ubiquitination degradation, leading to the activity reduction of $\mathrm{Nrf} 2$ and its downstream genes including CAT, GPx, SOD, and HO-1 in the kidney of mice. However, troxerutin partly mimicked the effect of MG132, blocked the ill effect of BDE-47, and increased the Nrf2 activity, which is consistent with the previous report, in which polyphenol blunts the Nrf2 transcriptional depression [48].

The increase of NOX2 activity and the decrease of Nrf2 in the tissue cause harmful oxidative stress and then initiate apoptotic event. Apoptosis is mediated through intrinsic pathways and extrinsic pathways [49]. Oxidative stress mediates intrinsic apoptosis pathway and triggers event upstream of mitochondrial apoptosis in kidney tissue cells $[50,51]$. Bcl-2 family proteins are involved in intrinsic apoptosis pathway; therefore, the downregulation of $\mathrm{Bcl}-2 / \mathrm{Bax}$ ratio promotes the release of cytochrome $\mathrm{c}$ from the mitochondria to the cytoplasm under oxidative stress and then induces the forming of an apoptosome containing APAF-1, cytochrome c, and procaspase-9. Procaspase-9 is processed to cleaved caspase-9 via an intrinsic autocatalytic activity of itself, which allows caspase- 9 cleavage to activate the downstream executioners including caspase-3, caspase-6, and caspase- 7 and causes the cleavage of PARP and subsequent apoptosis. The extracellular pathways are also activated under stresses and promote the apoptosis protein expression of FAS, TNF $\alpha$, and caspase- 8 , further activate caspase- 3 , and trigger cell apoptosis. The previous data showed that caspase3 was significantly activated in the liver and cerebellum of mice after exposure to BDE-47 [52]. BDE-47 also increased the gene expression level of caspase-3, caspase-8, caspase- 9 , TNFR1, and Bax and impaired macrophage accessory cell function in a concentration-dependent manner [53]. We have demonstrated that BDE-47 could increase caspase-3 activity and Bax levels and decline Bcl-2 level in the liver of mice [16]. In this study, BDE-47 is further demonstrated to be able to elevate the ratio of $\mathrm{Bcl}-2 / \mathrm{Bax}$, promote the release of cytochrome $\mathrm{c}$ from the mitochondria to the cytoplasm, and increase the expression of apoptosis proteins including APAF-1, caspase- 9 , caspase- 3 , and PARP, resulting in triggering intracellular apoptosis pathway. In addition, we also find that BDE-47 increases the protein expression of FAS, FASL, and caspase- 8 , activating the extracellular apoptosis pathway. However, the treatment with troxerutin deletes the adverse effect caused by BDE-47 and blocks the number of TUNEL-positive cells in the kidney tissue of mice, which is similar to the result of troxerutin alleviating oxidative damage and kidney cell apoptosis induced by D-galactose [54].

In summary, BDE-47 treatment for a long time enhances the ubiquitination of Nrf2, lessens the activity of Nrf2 and its downstream antioxidative enzymes including SOD, GPx, and CAT, and promotes oxidative stress of kidney cells of mice, increasing mitochondrial cytochrome $\mathrm{c}$ into the cytoplasm, triggering the mitochondrial apoptosis pathway. On the 
other hand, BDE-47 increases the expression of FAS, FASL, and caspase-8, starting up an extrinsic pathway. Furthermore, troxerutin inhibits these disadvantages induced by BDE-47 and decreases intrinsic and extrinsic apoptosis pathway, protecting kidney cells from oxidative stressinduced apoptosis damage.

\section{Abbreviations}

$\begin{array}{ll}\text { ROS: } & \text { Reactive oxygen species } \\ \text { DCFH-DA: } & \text { Dichlorofluorescein diacetate } \\ \text { BDE-47: } & 2,2^{\prime}, 4,4^{\prime} \text {-Tetrabromodiphenyl ether } \\ \text { PBDEs: } & \text { Polybrominated diphenyl ethers } \\ \text { POPs: } & \text { Persistent organic pollutants } \\ \text { T3: } & \text { Triiodothyronine } \\ \text { T4: } & \text { Tetraiodothyronine } \\ \text { GSH: } & \text { Glutathione } \\ \text { SOD: } & \text { Superoxide dismutase } \\ \text { CAT: } & \text { Catalase } \\ \text { GPx: } & \text { Glutathione peroxidase } \\ \text { TUNEL: } & \text { Terminal deoxynucleotidyl transferase-mediated } \\ & \text { dUTP nick end labeling } \\ \text { APAF-1: } & \text { Apoptosome containing apoptosis protease- } \\ & \text { activating factor-1 } \\ \text { PARP: } & \text { Poly ADP ribose polymerase } \\ \text { HO-1: } & \text { Heme oxygenase-1 } \\ \text { Bcl-2: } & \text { B-cell lymphoma-2 } \\ \text { Bax: } & \text { Bcl-2-associated X protein } \\ \text { FAS: } & \text { Factor-associated suicide } \\ \text { FASL: } & \text { Fas ligand } \\ \text { Nrf2: } & \text { Nuclear factor E2-related factor 2 } \\ \text { NOX2: } & \text { Nicotinamide adenine dinucleotide phosphate } \\ \text { PBS: } & \text { oxidase 2 } \\ \text { DAPI: } & \text { Phosphate buffer saline solution } \\ \text { SDS-PAGE: } & \text { Sodium dodecyl sulfate polyacrylamide gel } \\ & \text { electrophoresis } \\ \text { PVDF: } & \text { Polyvinylidenedifluoride membrane } \\ \text { BSA: } & \text { Bovine serum albumin } \\ \text { TBS: } & \text { Tris-buffered saline } \\ \text { NF- } \kappa B: ~ & \text { Nuclear factor kappa B } \\ \text { IL-6: } & \text { Interleukin } 6 . \\ & \end{array}$

\section{Conflicts of Interest}

The authors declare that there is no conflict of interests regarding the publication of this paper.

\section{Acknowledgments}

This work was supported by the National Natural Science Foundation of China (31200873 to Qun Shan, 81171012 to Yuanlin Zheng, 81271225 to Jun Lu, and 81400902 to D.M.W.) and funded by the Priority Academic Program Development of Jiangsu Higher Education Institutions (PAPD), the 2016 "333 Project” Award of Jiangsu Province, the 2013 "Qinglan Project" of the Young and Middle-aged Academic Leader of Jiangsu College and University, the Major Fundamental Research Program of the Natural
Science Foundation of the Jiangsu Higher Education Institutions of China (13KJA180001), and grants from the Graduate Student Innovation Program of Jiangsu Province (KYZZ16_04678 to Guihong Zheng).

\section{References}

[1] J. M. Sanders, L. J. Chen, E. H. Lebetkin, and L. T. Burka, "Metabolism and disposition of 2,2',4,4'-tetrabromodiphenyl ether following administration of single or multiple doses to rats and mice," Xenobiotica, vol. 36, pp. 103-117, 2006.

[2] D. F. Staskal, J. J. Diliberto, and L. S. Birnbaum, "Disposition of BDE 47 in developing mice," Toxicological Sciences, vol. 90, pp. 309-316, 2006.

[3] C. Emond, J. H. Raymer, W. B. Studabaker, C. E. Garner, and L. S. Birnbaum, "A physiologically based pharmacokinetic model for developmental exposure to BDE-47 in rats," Toxicology and Applied Pharmacology, vol. 242, pp. 290-298, 2010.

[4] H. Hakk, J. K. Huwe, K. Murphy, and D. Rutherford, "Metabolism of 2,2,4,4'-tetrabromodiphenyl ether (BDE-47) in chickens," Journal of Agricultural and Food Chemistry, vol. 58, pp. 8757-8762, 2010.

[5] P. Eriksson, E. Jakobsson, and A. Fredriksson, "Brominated flame retardants: a novel class of developmental neurotoxicants in our environment?," Environmental Health Perspectives, vol. 109, pp. 903-908, 2001.

[6] M. M. Dingemans, G. M. Ramakers, F. Gardoni et al., "Neonatal exposure to brominated flame retardant BDE-47 reduces long-term potentiation and postsynaptic protein levels in mouse hippocampus," Environmental Health Perspectives, vol. 115, pp. 865-870, 2007.

[7] L. G. Costa and G. Giordano, "Developmental neurotoxicity of polybrominated diphenyl ether (PBDE) flame retardants," Neurotoxicology, vol. 28, pp. 1047-1067, 2007.

[8] P. He, W. He, A. Wang et al., "PBDE-47-induced oxidative stress, DNA damage and apoptosis in primary cultured rat hippocampal neurons," Neurotoxicology, vol. 29, pp. 124129, 2008.

[9] P. He, A. G. Wang, T. Xia et al., "Mechanism of the neurotoxic effect of PBDE-47 and interaction of PBDE-47 and PCB153 in enhancing toxicity in SH-SY5Y cells," Neurotoxicology, vol. 30, pp. 10-15, 2009.

[10] W. He, P. He, A. Wang, T. Xia, B. Xu, and X. Chen, "Effects of PBDE-47 on cytotoxicity and genotoxicity in human neuroblastoma cells in vitro," Mutation Research, vol. 649, pp. $62-$ 70, 2008.

[11] V. M. Richardson, D. F. Staskal, D. G. Ross, J. J. Diliberto, M. J. DeVito, and L. S. Birnbaum, "Possible mechanisms of thyroid hormone disruption in mice by BDE 47, a major polybrominated diphenyl ether congener," Toxicology and Applied Pharmacology, vol. 226, pp. 244-250, 2008.

[12] H. Wu, L. Cao, F. Li, P. Lian, and J. Zhao, "Multiple biomarkers of the cytotoxicity induced by BDE-47 in human embryonic kidney cells," Chemosphere, vol. 126, pp. 32-39, 2015.

[13] H. R. Park and R. Loch-Caruso, "Protective effect of $( \pm) \alpha$ tocopherol on brominated diphenyl ether-47-stimulated prostaglandin pathways in human extravillous trophoblasts in vitro," Toxicology In Vitro, vol. 29, pp. 1309-1318, 2015.

[14] A. Yeh, S. E. Kruse, D. J. Marcinek, and E. P. Gallagher, "Effect of omega-3 fatty acid oxidation products on the cellular and 
mitochondrial toxicity of BDE 47," Toxicology In Vitro, vol. 29, pp. 672-680, 2015.

[15] Z. F. Zhang, Y. Q. Zhang, S. H. Fan et al., “Troxerutin protects against 2,2'4,4'-tetrabromodiphenyl ether (BDE-47)-induced liver inflammation by attenuating oxidative stress-mediated $\mathrm{NAD}^{+}$-depletion," Journal of Hazardous Materials, vol. 283, pp. 98-109, 2015.

[16] Z. F. Zhang, Q. Shan, J. Zhuang et al., “Troxerutin inhibits 2,2',4,4'-tetrabromodiphenyl ether (BDE-47)-induced hepatocyte apoptosis by restoring proteasome function," Toxicology Letters, vol. 233, pp. 246-257, 2015.

[17] N. A. Bergstein, "Clinical study on the efficacy of O-( $\beta$-hydroxyethyl) rutoside (HR) in varicosis of pregnancy," The Journal of International Medical Research, vol. 3, pp. 189-193, 1975.

[18] K. Sumboonnanonda and P. Lertsithichai, "Clinical study of the Ginko biloba-Troxerutin-Heptaminol Hce in the treatment of acute hemorrhoidal attacks," Journal of the Medical Association of Thailand, vol. 87, pp. 137-142, 2004.

[19] W. Vanscheidt, E. Rabe, B. Naser-Hijazi et al., "The efficacy and safety of a coumarin-/troxerutin-combination (SB-LOT) in patients with chronic venous insufficiency: a double blind placebo-controlled randomised study," Vasa, vol. 31, pp. 185-190, 2002.

[20] S. Babri, G. Mohaddes, I. Feizi et al., "Effect of troxerutin on synaptic plasticity of hippocampal dentate gyrus neurons in a $\beta$-amyloid model of Alzheimer's disease: an electrophysiological study," European Journal of Pharmacology, vol. 732, pp. 19-25, 2014.

[21] S. Sampath and B. Karundevi, "Effect of troxerutin on insulin signaling molecules in the gastrocnemius muscle of high fat and sucrose-induced type-2 diabetic adult male rat," Molecular and Cellular Biochemistry, vol. 395, pp. 11-27, 2014.

[22] Z. F. Zhang, S. H. Fan, Y. L. Zheng et al., "Troxerutin protects the mouse liver against oxidative stress-mediated injury induced by D-galactose," Journal of Agricultural and Food Chemistry, vol. 57, pp. 7731-7736, 2009.

[23] J. Lu, D. M. Wu, B. Hu et al., "Chronic administration of troxerutin protects mouse brain against D-galactose-induced impairment of cholinergic system," Neurobiology of Learning and Memory, vol. 93, pp. 157-164, 2010.

[24] S. H. Fan, Z. F. Zhang, Y. L. Zheng et al., "Troxerutin protects the mouse kidney from d-galactose-caused injury through anti-inflammation and anti-oxidation," International Immunopharmacology, vol. 9, pp. 91-96, 2009.

[25] J. Lu, D. M. Wu, Z. H. Zheng, Y. L. Zheng, B. Hu, and Z. F. Zhang, "Troxerutin protects against high cholesterol-induced cognitive deficits in mice," Brain, vol. 134, pp. 783-797, 2011.

[26] J. Lu, D. M. Wu, Y. L. Zheng et al., "Troxerutin counteracts domoic acid-induced memory deficits in mice by inhibiting CCAAT/enhancer binding protein $\beta$-mediated inflammatory response and oxidative stress," Journal of Immunology, vol. 190, pp. 3466-7349, 2013.

[27] Z. F. Zhang, S. H. Fan, Y. L. Zheng et al., "Troxerutin improves hepatic lipid homeostasis by restoring $\mathrm{NAD}^{+}$-depletion-mediated dysfunction of lipin 1 signaling in high-fat diet-treated mice," Biochemical Pharmacology, vol. 91, pp. 74-86, 2014.

[28] J. L. Lim, M. M. Wilhelmus, H. E. de Vries, B. Drukarch, J. J. Hoozemans, and J. van Horssen, "Antioxidative defense mechanisms controlled by Nrf2: state-of-the-art and clinical perspectives in neurodegenerative diseases," Archives of Toxicology, vol. 88, pp. 1773-1786, 2014.
[29] K. Asaba, A. Tojo, M. L. Onozato et al., "Effects of NADPH oxidase inhibitor in diabetic nephropathy," Kidney International, vol. 67, pp. 1890-1898, 2005.

[30] F. Tao, M. Abou-Elwafa Abdallah, D. C. Ashworth, P. Douglas, M. B. Toledano, and S. Harrad, "Emerging and legacy flame retardants in UK human milk and food suggest slow response to restrictions on use of PBDEs and HBCDD," Environment International, vol. 105, pp. 95-104, 2017.

[31] H. Bjermo, M. Aune, T. Cantillana et al., "Serum levels of brominated flame retardants (BFRs: PBDE, HBCD) and influence of dietary factors in a population-based study on Swedish adults," Chemosphere, vol. 167, pp. 485-491, 2017.

[32] S. A. Marchitti, S. E. Fenton, P. Mendola, J. F. Kenneke, and E. P. Hines, "Polybrominated diphenyl ethers in human milk and serum from the U.S. EPA MAMA study: modeled predictions of infant exposure and considerations for risk assessment," Environmental Health Perspectives, vol. 125, pp. 706-713, 2017.

[33] M. H. Müller, A. Polder, O. B. Brynildsrud et al., "Brominated flame retardants (BFRs) in breast milk and associated health risks to nursing infants in Northern Tanzania," Environment International, vol. 89-90, pp. 38-47, 2016.

[34] Z. J. Chen, H. Y. Liu, K. L. Ho et al., "Hydroxylated polybrominated diphenyl ethers (OH-PBDEs) in paired maternal and neonatal samples from South China: placental transfer and potential risks," Environmental Research, vol. 148, pp. 72-78, 2016.

[35] S. A. Marchitti, C. S. Mazur, C. M. Dillingham et al., "Inhibition of the human ABC efflux transporters P-gp and BCRP by the BDE-47 hydroxylated metabolite $6-\mathrm{OH}-\mathrm{BDE}-47$ : considerations for human exposure," Toxicological Sciences, vol. 155, pp. 270-282, 2017.

[36] Q. Saquib, M. A. Siddiqui, J. Ahmed et al., "Hazards of low dose flame-retardants (BDE-47 and BDE-32): influence on transcriptome regulation and cell death in human liver cells," Journal of Hazardous Materials, vol. 308, pp. 37-49, 2016.

[37] C. Jiang, S. Zhang, H. Liu et al., “The role of the IRE1 pathway in PBDE-47-induced toxicity in human neuroblastoma SHSY5Y cells in vitro," Toxicology Letters, vol. 211, pp. 325-333, 2012.

[38] C. Yan, D. Huang, and Y. Zhang, "The involvement of ROS overproduction and mitochondrial dysfunction in PBDE-47induced apoptosis on Jurkat cells," Experimental and Toxicologic Pathology, vol. 63, pp. 413-417, 2011.

[39] Z. Zhang, S. Li, L. Liu et al., "Environmental exposure to BDE47 is associated with increased diabetes prevalence: evidence from community-based case-control studies and an animal experiment," Scientific Reports, vol. 6, article 27854, 2016.

[40] Z. Zhang, Y. Yu, H. Xu et al., "High-fat diet aggravates 2,2',4,4'tetrabromodiphenyl ether-inhibited testosterone production via DAX-1 in Leydig cells in rats," Toxicology and Applied Pharmacology, vol. 323, pp. 1-8, 2017.

[41] L. M. Fan, S. Cahill-Smith, L. Geng, J. Du, G. Brooks, and J. M. $\mathrm{Li}$, "Aging-associated metabolic disorder induces Nox2 activation and oxidative damage of endothelial function," Free Radical Biology \& Medicine, vol. 108, pp. 940-951, 2017.

[42] J. Lu, D. M. Wu, Y. L. Zheng, B. Hu, W. Cheng, and Z. F. Zhang, "Purple sweet potato color attenuates domoic acidinduced cognitive deficits by promoting estrogen receptor- $\alpha$ mediated mitochondrial biogenesis signaling in mice," Free Radical Biology \& Medicine, vol. 52, pp. 646-659, 2012. 
[43] M. A. Aminzadeh, S. B. Nicholas, K. C. Norris, and N. D. Vaziri, "Role of impaired Nrf2 activation in the pathogenesis of oxidative stress and inflammation in chronic tubulointerstitial nephropathy," Nephrology, Dialysis, Transplantation, vol. 28, pp. 2038-2045, 2013.

[44] A. S. Arellano-Buendía, M. Tostado-González, F. E. GarcíaArroyo et al., "Anti-inflammatory therapy modulates Nrf2Keap1 in kidney from rats with diabetes," Oxidative Medicine and Cellular Longevity, vol. 2016, Article ID 4693801, 11 pages, 2016.

[45] L. Kong, Y. Wang, M. Luo, Y. Tan, W. Cui, and L. Miao, "Prevention of streptozotocin-induced diabetic nephropathy by MG132: possible roles of Nrf2 and I $\kappa \mathrm{B}$," Oxidative Medicine and Cellular Longevity, vol. 2017, Article ID 3671751, 12 pages, 2017.

[46] H. R. Park and R. Loch-Caruso, "Protective effect of nuclear factor E2-related factor 2 on inflammatory cytokine response to brominated diphenyl ether-47 in the HTR-8/SVneo human first trimester extravillous trophoblast cell line," Toxicology and Applied Pharmacology, vol. 281, pp. 67-77, 2014.

[47] W. Sun, X. Liu, H. Zhang et al., "Epigallocatechin gallate upregulates NRF2 to prevent diabetic nephropathy via disabling KEAP1," Free Radical Biology \& Medicine, vol. 108, pp. 840-857, 2017.

[48] H. K. Bayele, E. S. Debnam, and K. S. Srai, "Nrf2 transcriptional derepression from Keap1 by dietary polyphenols," Biochemical and Biophysical Research Communications, vol. 469, pp. 521-528, 2016.

[49] S. Elmore, "Apoptosis: a review of programmed cell death," Toxicologic Pathology, vol. 35, pp. 495-516, 2007.

[50] B. D. Sahu, S. Tatireddy, M. Koneru et al., "Naringin ameliorates gentamicin-induced nephrotoxicity and associated mitochondrial dysfunction, apoptosis and inflammation in rats: possible mechanism of nephroprotection," Toxicology and Applied Pharmacology, vol. 277, pp. 8-20, 2014.

[51] I. Burlaka, L. M. Nilsson, L. Scott et al., "Prevention of apoptosis averts glomerular tubular disconnection and podocyte loss in proteinuric kidney disease," Kidney International, vol. 90, pp. 135-148, 2016.

[52] L. G. Costa, C. Pellacani, K. Dao, T. J. Kavanagh, and P. J. Roque, "The brominated flame retardant BDE-47 causes oxidative stress and apoptotic cell death in vitro and in vivo in mice," Neurotoxicology, vol. 48, pp. 68-76, 2015.

[53] Q. Y. Lv, B. Wan, L. H. Guo, L. Zhao, and Y. Yang, "In vitro immune toxicity of polybrominated diphenyl ethers on murine peritoneal macrophages: apoptosis and immune cell dysfunction," Chemosphere, vol. 120, pp. 621-630, 2015.

[54] C. M. Liu, J. Q. Ma, and Y. Lou, "Chronic administration of troxerutin protects mouse kidney against D-galactoseinduced oxidative DNA damage," Food and Chemical Toxicology, vol. 48, pp. 2809-2817, 2010. 


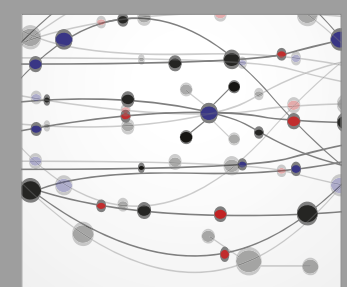

The Scientific World Journal
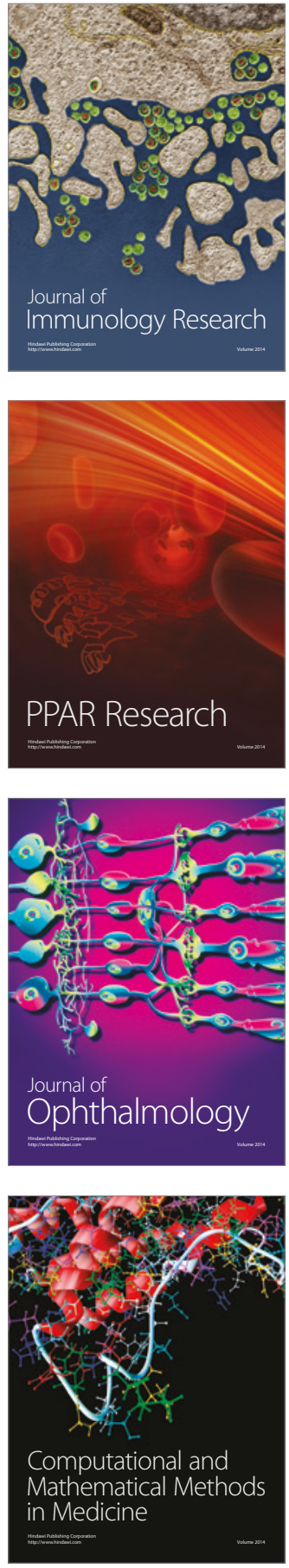

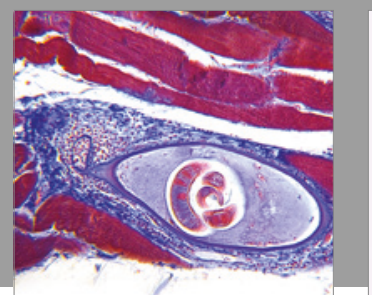

Gastroenterology Research and Practice
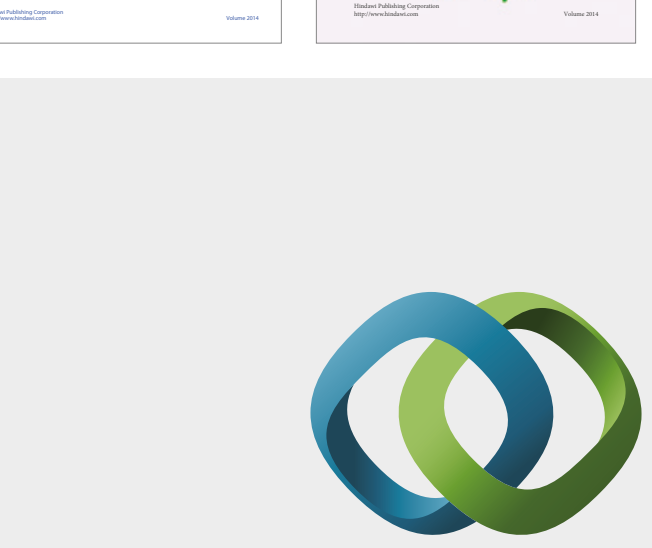

\section{Hindawi}

Submit your manuscripts at

https://www.hindawi.com
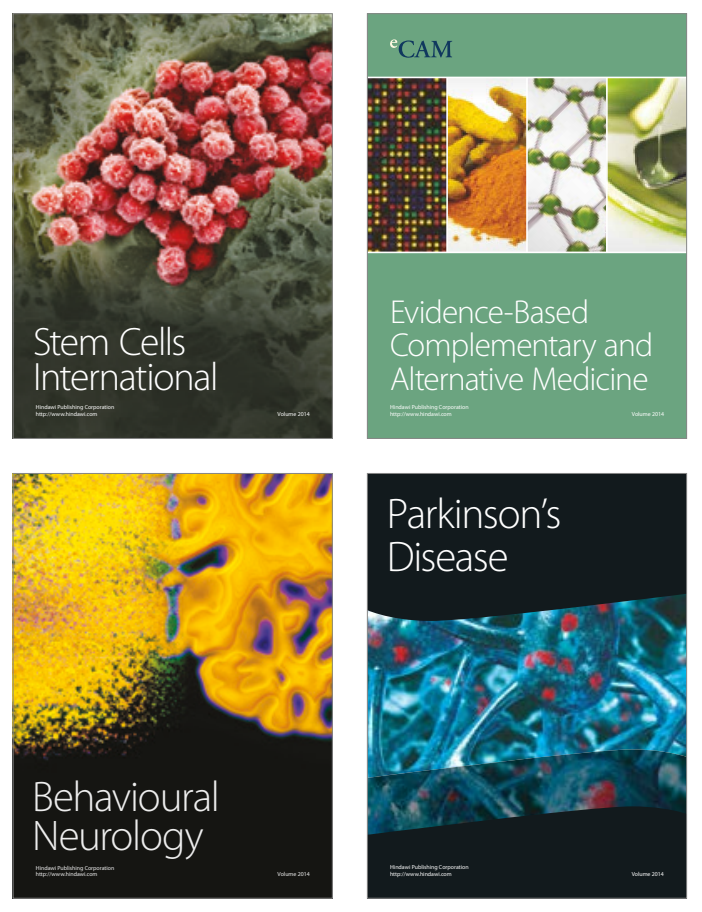
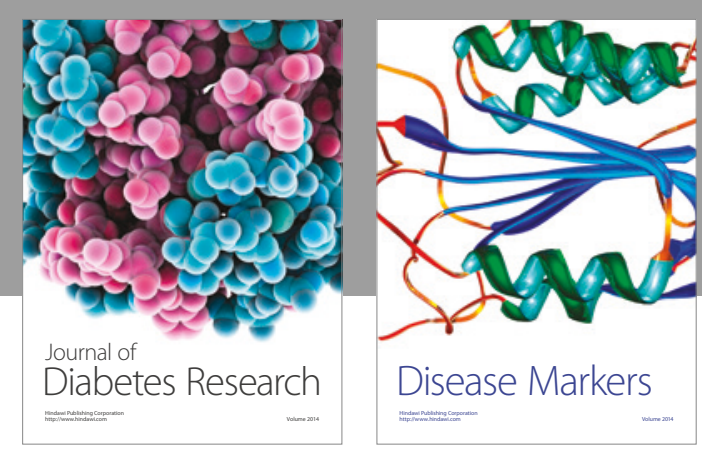

Disease Markers
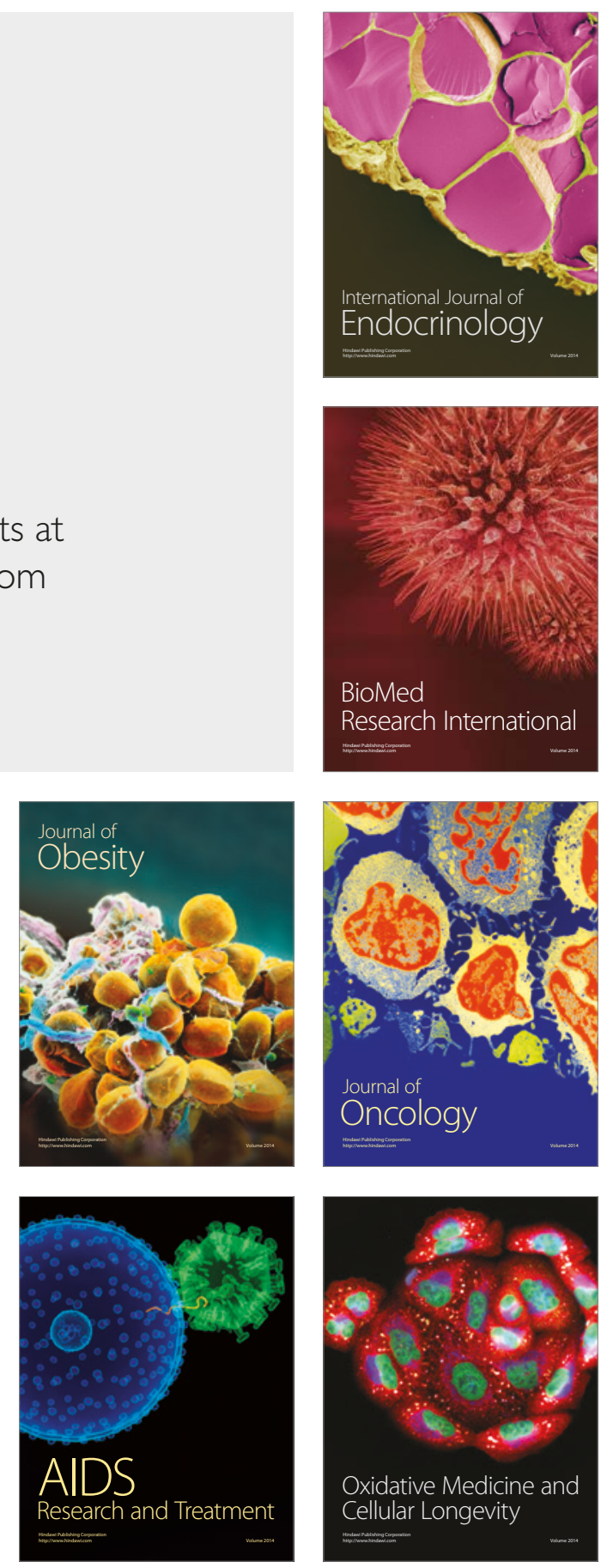